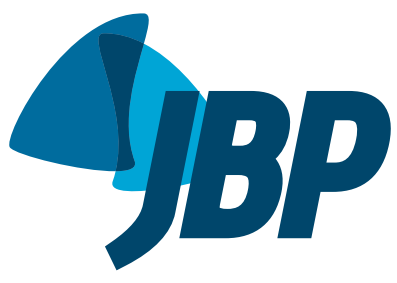

\title{
Assessment of theoretical and practical knowledge of asthma among guardians of children treated in primary care
}

\author{
Cathiana Carmo Dalto Banhos ${ }^{1, a}$, Cristian Roncada ${ }^{2, b}$, Leonardo Araújo Pinto ${ }^{3, c}$, \\ Paulo Márcio Pitrez $z^{4,5, d}$
}

\section{TO THE EDITOR}

Asthma is a highly prevalent chronic respiratory disease and constitutes a serious global public health problem. Its management is related to symptom control. Asthma control requires knowledge of the disease, because children depend on their guardians for asthma management. ${ }^{(2)}$ Studies have demonstrated that only $50 \%$ of patients achieve symptom control through treatment adherence as instructed by a health care team. ${ }^{(3)}$ Inhaled medication use, with correct inhaler technique, reevaluation visits by a multidisciplinary team, and changes in lifestyle habits are strategic measures in the treatment of asthma in childhood. ${ }^{(4)}$

Therefore, a cross-sectional study was designed with the objective of assessing the health literacy and asthma knowledge levels of guardians of children and adolescents (1-17 years old) diagnosed with the disease and registered in the Rede Bem-Estar (Wellbeing Network) in the city of Vitória, Brazil. The study was approved by the local research ethics committee (Protocol no. 2.257.264), and written informed consent was obtained from all participants. Patient selection included five health care facilities that were chosen by convenience sampling. We excluded patients with cognitive or motor limitations or with other chronic diseases that could compromise the evaluation of health control, attitudes, and practices.

The diagnosis of asthma was made by a pediatrician working in the municipal health care system in the city of Vitória, in accordance with the tenth revision of the International Classification of Diseases (code J45). Patient follow-up in primary care is carried out jointly by a Family Health Program physician and a specialist physician (pediatrician).

Patients' guardians were administered a clinical questionnaire and a socioeconomic classification questionnaire. ${ }^{(5)}$ For assessment of asthma control, they completed the Global Initiative for Asthma questionnaire, ${ }^{(1)}$ which categorizes asthma control levels (as controlled, partly controlled, and uncontrolled). For assessment of disease knowledge, they were administered a specific questionnaire on knowledge of pediatric asthma (Newcastle Asthma Knowledge Questionnaire) ${ }^{(6)}$ and a health literacy questionnaire (Short Assessment of Health Literacy for Portuguese-speaking Adults). (7) For assessment of treatment attitudes and practices, they were administered a theoretical questionnaire and underwent observational practice analysis regarding the specific management for treating asthma. For analysis of understanding of prescription instructions, the guardians were assessed as to the type of prescription (preventive or rescue) and their understanding of the prescription instructions; their level of understanding was classified as adequate or inadequate. For the purpose of establishing cut-off points for the questionnaires, scores of at least $70 \%(\geq$ 7 points) were considered acceptable. For the purpose of statistical analysis, the chi-square test was used for nominal variables, and ANOVA with the Bonferroni post hoc test was used for scalar variables.

A total of 120 children with asthma, with a mean age of $6.3 \pm 3.9$ years, participated in the study. Their guardians had a mean age of $39.9 \pm 13.0$ years, and it was the mothers who predominantly took their children to medical appointments $(n=94 ; 78.3 \%)$. A total of $45.0 \%$ of the guardians had completed high school, and $48.3 \%$ belonged to the middle socioeconomic class (class $\mathrm{C}$ ).

Comparison of results by asthma control group (Table 1) showed significant differences for the following variables: symptoms of chest tightness ever $(p=0.02)$; wheezing or shortness of breath at rest $(p=0.02)$; hospitalization for asthma ( $p=0.01)$; and school absenteeism $(p=0.01)$. In addition, the results regarding asthma treatment in the past 12 months showed that the totally controlled asthma group had the highest proportion of patients receiving continuous treatment $(p<0.01)$ and the lowest proportions of patients using oral corticosteroids $(p=0.01)$ and bronchodilators $(p=0.01)$.

In the assessment of inhalation techniques, the results revealed poor theoretical knowledge of the techniques, with no differences between the groups $(p=0.08)$. However, the frequency of guardians with adequate practical knowledge of inhalation techniques was significantly higher in the totally controlled asthma group than in the other groups $(p<0.01)$. In the assessment of prescription literacy and understanding of prescription instructions and type of treatment, the results showed that guardians of children with greater asthma control have a better understanding of the disease. In the assessment of health literacy, there

1. Programa de Pós-Graduação em Pediatria e Saúde da Criança, Faculdade de Medicina, Pontifícia Universidade Católica do Rio Grande do Sul - PUCRS - Porto Alegre (RS) Brasil.

2. Grupo de Estudo e Pesquisa em Saúde e Performance - GEPESP - Centro Universitário da Serra Gaúcha, Caxias do Sul (RS) Brasil.

3. Centro Infant, Instituto de Pesquisas Biomédicas, Pontifícia Universidade Católica do Rio Grande do Sul - PUCRS - Porto Alegre (RS) Brasil.

4. Hospital São Lucas, Pontifícia Universidade Católica do Rio Grande do Sul - PUCRS - Porto Alegre (RS) Brasil.

5. Hospital Moinhos de Vento, Porto Alegre (RS) Brasil.

a. (iD) http://orcid.org/0000-0001-7182-8962; b. (iD) http://orcid.org/0000-0003-3782-4911; c. (iD http://orcid.org/0000-0002-4067-7468;

d. (iD) http://orcid.org/0000-0001-7319-1133 
Table 1. Asthma diagnoses, asthma symptoms, and asthma treatment, by asthma control classification. ${ }^{a}$

\begin{tabular}{|c|c|c|c|c|}
\hline \multirow[t]{2}{*}{ Variable } & \multicolumn{3}{|c|}{ Asthma } & \multirow[t]{2}{*}{$\mathbf{p}$} \\
\hline & $\begin{array}{l}\text { Uncontrolled } \\
\qquad(\mathrm{n}=75)\end{array}$ & $\begin{array}{c}\text { Partly } \\
\text { controlled } \\
\text { (n }=11)\end{array}$ & $\begin{array}{l}\text { Totally } \\
\text { controlled } \\
(n=34)\end{array}$ & \\
\hline Diagnosis of rhinitis & $59(78.7)$ & $9(81.8)$ & $32(94.1)$ & 0.13 \\
\hline Diagnosis of atopy & $42(56.0)$ & $7(63.6)$ & $20(58.8)$ & 0.88 \\
\hline \multicolumn{5}{|l|}{ Asthma symptoms (ever) } \\
\hline Woken up with shortness of breath & $73(97.3)$ & $11(100.0)$ & $34(100.0)$ & 0.55 \\
\hline Woken up with chest tightness & $43(57.3)$ & $11(100.0)$ & $23(67.6)$ & $0.02^{* *}$ \\
\hline \multicolumn{5}{|l|}{ Asthma symptoms (in the past 12 months) } \\
\hline Wheezing/shortness of breath during exercise & $47(62.7)$ & $9(81.8)$ & $18(52.9)$ & 0.22 \\
\hline Wheezing/shortness of breath at rest & $66(88.0)$ & $10(90.9)$ & $23(67.6)$ & $0.02^{*}$ \\
\hline Hospitalization for asthma & $43(57.3)$ & $9(81.8)$ & $12(35.3)$ & $0.01^{* *}$ \\
\hline Only once & $40(93.0)$ & $8(88.9)$ & $12(100.0)$ & $0.01^{* *}$ \\
\hline Twice or more & $3(7.0)$ & $1(11.1)$ & $0(0.0)$ & \\
\hline School absenteeism in the last school year & $70(93.3)$ & $11(100.0)$ & $26(76.5)$ & $0.01^{*}$ \\
\hline One full week & $6(8.0)$ & $2(18.2)$ & $5(14.7)$ & $0.01^{*}$ \\
\hline Two full weeks & $24(32.0)$ & $4(36.4)$ & $12(35.3)$ & \\
\hline More than two weeks & $40(53.3)$ & $5(45.5)$ & $9(26.5)$ & \\
\hline \multicolumn{5}{|l|}{ Asthma treatment (in the past 12 months) } \\
\hline Has a prescription for medication to treat asthma attacks & $70(93.3)$ & $11(100.0)$ & $34(100.0)$ & 0.21 \\
\hline Continuous treatment & $41(54.7)$ & $9(81.8)$ & $34(100.0)$ & $<0.01^{* *}$ \\
\hline Takes treatment before exercise & $43(57.3)$ & $8(72.7)$ & $14(41.2)$ & 0.13 \\
\hline Treatment with inhaled corticosteroids & $70(93.3)$ & $11(100.0)$ & $34(100.0)$ & 0.21 \\
\hline Treatment with oral corticosteroids & $63(84.0)$ & $9(81.8)$ & $20(58.8)$ & $0.01^{*}$ \\
\hline Treatment with bronchodilators & $75(100.0)$ & $11(100.0)$ & $30(88.2)$ & $0.01^{*}$ \\
\hline Treatment with leukotriene receptor antagonists & $3(4.0)$ & $0(0.0)$ & $3(8.8)$ & 0.41 \\
\hline Recieves medication via the public health care system & $74(98.7)$ & $11(100.0)$ & $34(100.0)$ & 0.74 \\
\hline Uses a spacer for the treatment & $59(78.7)$ & $11(100.0)$ & $29(85.3)$ & 0.20 \\
\hline Uses a commercial spacer & $58(98.3)$ & $11(100.0)$ & $29(100.0)$ & 0.71 \\
\hline
\end{tabular}

${ }^{a}$ Values expressed as $\mathrm{n}(\%) .{ }^{*} \mathrm{p}<0.05$ between the totally controlled asthma group and the other groups. **p $<$ 0.05 between the three asthma control groups.

were no statistically significant differences between the asthma control groups. In contrast, in the assessment of asthma knowledge, values were lower in the partly controlled asthma group than in the other groups $(p=0.02)$. With regard to prescription literacy and understanding of prescription instructions and type of treatment, we found that greater understanding of the procedures for proper treatment indicates better disease control scores.

Another relevant finding concerns asthma control through continuous, preventive treatment. All patients with totally controlled and partly controlled asthma had prescriptions for medication to treat asthma attacks. In addition, adherence to continuous treatment was better in the totally controlled and partly controlled asthma groups ( $100.0 \%$ and $81.8 \%$, respectively). However, in the uncontrolled asthma group, $54.7 \%$ of the patients were adherent to continuous treatment, and a predominant number of patients used inhaled and oral corticosteroids.
The present study demonstrates that the vast majority of children with asthma do not have controlled disease, and inadequate asthma control is due to lower use of controller medication. In addition, rescue medications and oral corticosteroids were demonstrated to be very frequently used by patients with partly controlled or uncontrolled asthma. Another important factor concerns prescription literacy and understanding of prescription instructions and type of treatment: greater understanding of the procedures for proper treatment translates to better disease control.

Limitations to this study include the type of design (cross-sectional) with one-time assessment, the non-probabilistic (convenience) sampling, and the age range studied.

Finally, our findings underscore the need for improving asthma knowledge in the groups studied in order to increase disease control through parent and patient educational programs that are central to and effective in consolidating public policies aimed at health promotion.

\section{REFERENCES}

Bateman ED, Hurd SS, Barnes PJ, Bousquet J, Drazen JM, FitzGerald $\mathrm{JM}$, et al. Global strategy for asthma management and prevention:
GINA executive summary. Eur Respir J. 2008;31(1):143-78. https:// doi.org/10.1183/09031936.00138707 
2. Cardoso TA, Roncada C, Silva ERD, Pinto LA, Jones MH, Stein RT, et al. The impact of asthma in Brazil: a longitudinal analysis of data from a Brazilian national database system. J Bras Pneumol. 2017;43(3):163168. https://doi.org/10.1590/s1806-37562016000000352

3. Roncada C, Oliveira SG, Cidade SF, Rafael JG, Ojeda BS, Santos $B R$, et al. Asthma treatment in children and adolescents in an urban area in southern Brazil: popular myths and features. J Bras Pneumol. 2016;42(2):136-42. https://doi.org/10.1590/S180637562015000000166

4. Roncada C, Cardoso TA, Bugança BM, Bischoff LC, Soldera K, Pitrez PM. Levels of knowledge about asthma of parents of asthmatic children. Einstein (Sao Paulo). 2018;16(2):eAO4204. https://doi. org/10.1590/s1679-45082018a04204
5. Associação Brasileira de Empresas de Pesquisa. Critério de classificação econômica Brasil. São Paulo: Associação Nacional de Empresas de Pesquisa; 2013

6. Cidade SF, Roncada C, Costa DD, Rafael JG, Pitrez PM. Linguistic and psychometric validation of the questionnaire Newcastle Asthma Knowledge Questionnaire on knowledge of asthma [Article in Portuguese]. Rev Cienc Med (Campinas). 2016;24(2):45-54. https:// doi.org/10.24220/2318-0897v24n2a2422

7. Apolinario D, Braga Rde $C$, Magaldi RM, Busse AL, Campora F, Brucki S, et al. Short Assessment of Health Literacy for Portuguesespeaking Adults. Rev Saude Publica. 2012;46(4):702-11. https://doi. org/10.1590/S0034-89102012005000047 